\title{
Synergistic effects of nelfinavir and bortezomib on proteotoxic death of NSCLC and multiple myeloma cells
}

\author{
S Kawabata ${ }^{1}$, JJ Gills ${ }^{1}$, JR Mercado-Matos ${ }^{1}$, J LoPiccolo ${ }^{1}$, W Wilson III ${ }^{1}$ MC Hollander ${ }^{1}$ and PA Dennis, ${ }^{*}$
}

Exploiting protein homeostasis is a new therapeutic approach in cancer. Nelfinavir (NFV) is an HIV protease inhibitor that induces endoplasmic reticulum (ER) stress in cancer cells. Under conditions of ER stress, misfolded proteins are transported from the ER back to the cytosol for subsequent degradation by the ubiquitin-proteasome system. Bortezomib (BZ) is a proteasome inhibitor and interferes with degradation of misfolded proteins. Here, we show that NFV and BZ enhance proteotoxicity in non-small cell lung cancer (NSCLC) and multiple myeloma (MM) cells. The combination synergistically inhibited cell proliferation and induced cell death. Activating transcription factor (ATF)3 and CCAAT-enhancer binding protein homologous protein (CHOP), markers of ER stress, were rapidly increased, and their siRNA-mediated knockdown inhibited cell death. Knockdown of double-stranded RNA activated protein kinase-like ER kinase, a signal transducer in ER stress, significantly decreased apoptosis. Pretreatment with the protein synthesis inhibitor, cycloheximide, decreased levels of ubiquitinated proteins, ATF3, CHOP, and the overall total cell death, suggesting that inhibition of protein synthesis increases cell survival by relieving proteotoxic stress. The NFV/BZ combination inhibited the growth of NSCLC xenografts, which correlated with the induction of markers of ER stress and apoptosis. Collectively, these data show that NFV and BZ enhance proteotoxicity in NSCLC and MM cells, and suggest that this combination could tip the precarious balance of protein homeostasis in cancer cells for therapeutic gain.

Cell Death and Disease (2012) 3, e353; doi:10.1038/cddis.2012.87; published online 19 July 2012

Subject Category: Cancer

Cellular protein homeostasis is maintained through regulation of protein synthesis, folding, and degradation. An imbalance can lead to proteotoxic stress due to accumulation of misfolded proteins, resulting in harmful cellular effects known as proteotoxicity. ${ }^{1}$ Cancer cells have high rates of protein synthesis and folding, making them potentially vulnerable to proteotoxicity. Cells respond to proteotoxic stress in a compartment-specific manner. For example, the heat-shock response is triggered by proteotoxic stress in the cytosol, and the unfolded protein response (UPR) is activated by misfolded proteins in the endoplasmic reticulum (ER), a condition referred to as ER stress. ${ }^{2}$

Once activated, the heat-shock response and UPR allow the cell to cope with proteotoxic stress by decreasing protein translation and increasing rates of protein refolding and degradation. If the stress is not relieved, apoptosis may ensue. $^{3,4}$ The ubiquitin-proteasome system (UPS) is responsible for the majority of protein turnover in a cell. Lysine-48linked ubiquitin chains mark proteins destined for degradation by the proteasome in the cytosol. Under conditions of ER stress, misfolded proteins are transported from the ER back to the cytosol for subsequent degradation by the UPS, a process known as ER-associated protein degradation (ERAD). ${ }^{5}$
Proteotoxicity has emerged as a novel therapeutic strategy in cancer. ${ }^{6}$ Proof of concept came with US Food and Drug Administration (FDA) approval of the $26 \mathrm{~S}$ proteasome inhibitor (bortezomib (BZ)) for treatment of multiple myeloma (MM). ${ }^{7}$ BZ causes accumulation of ubiquitinated protein (Ubprotein) aggregates, ER stress, and apoptosis. ${ }^{8}$ Inhibitors of the chaperone heat-shock protein (HSP) 90 are another class of drugs that causes proteotoxicity and are currently in clinical trials. ${ }^{9}$ Newer approaches are also being studied. For example, histone deacetylase 6 (HDAC6) is a positive regulator of HSP90, and HDAC6 inhibition causes accumulation of misfolded proteins for proteotoxicity. ${ }^{10,11}$ In addition, inhibitors of ERAD and dephosphorylation of eukaryotic initiation factor-2 alpha (elF2 $\alpha$ ) are reported to enhance proteotoxicity in cancer cells, ${ }^{12,13}$ suggesting that the induction of proteotoxicity might be an effective therapeutic strategy.

Nelfinavir (NFV) is an HIV protease inhibitor that is currently being repositioned as a cancer therapeutic and is being evaluated in oncology clinical trials. ${ }^{14}$ Our group has shown NFV induces ER stress and apoptosis, and inhibits proliferation in a broad spectrum of cancer cell types, including nonsmall cell lung cancer (NSCLC) and MM cells. ${ }^{15}$ As BZ

\footnotetext{
${ }^{1}$ Medical Oncology Branch, Center for Cancer Research, National Cancer Institute, Bethesda, MD 20892, USA

${ }^{*}$ Corresponding author: PA Dennis, Medical Oncology Branch, Center for Cancer Research, National Cancer Institute, 37 Convent Drive, Room 1042A, Bethesda, MD 20892, USA. Tel: 301496 0929; Fax: 301435 4345; E-mail: pdennis@jhmi.edu

Keywords: proteotoxicity; ER stress; nelfinavir; bortezomib; lung cancer

Abbreviations: ATF, activating transcription factor; CHOP, CCAAT-enhancer binding protein homologous protein; PERK, double-stranded RNA activated protein kinase-like endoplasmic reticulum kinase; elF2 $\alpha$, eukaryotic initiation factor-2 alpha; IRE1 $\alpha$, inositol requiring 1 alpha; XBP- $1^{\mathrm{s}}$, spliced X-box-binding protein 1

Received 23.3.12; revised 24.5.12; accepted 31.5.12; Edited by G Ciliberto
} 
interferes with ERAD by proteasome inhibition, we hypothesized that the combination of NFV and BZ might have enhanced efficacy by exceeding the capacity of cancer cells to cope with proteotoxic stress. To test our hypothesis, we evaluated the contribution of both proteotoxic stress in the cytosol and ER stress on the efficacy of the combination utilizing NSCLC and MM cells. Our data demonstrate that combining NFV with BZ enhances proteotoxicity in vitro and in vivo.

\section{Results}

NFV and BZ synergistically inhibit proliferation of NSCLC and MM cells. To assess effects on cellular proliferation, NFV and $\mathrm{BZ}$ were tested at concentrations that are clinically achievable. The combination of NFV and BZ decreased proliferation more than either drug alone in two NSCLC (Figure 1a, left panels) and two MM (right panels) cell lines. To evaluate synergy, combination indices (Cls) were calculated using CalcuSyn software. Computer-simulated $\mathrm{Fa}-\mathrm{Cl}$ curves showed synergism $(\mathrm{Cls}<1)$ in the four cell lines evaluated (Figure $1 \mathrm{~b}$ and Supplementary Table 1A). In addition, the combination showed synergism in RPMI8226 V10R and Kas-6 V10R MM cells that are BZ-resistant (Figures 1c and d, and Supplementary Table 1B). These data show that the combination synergistically decreases cellular proliferation.

\section{Combining NFV with BZ enhances caspase-dependent} apoptosis. NFV and BZ reduced cell numbers below that at the start of the proliferation experiments (\% growth <0). Therefore, early apoptosis was measured by Annexin $V$ binding assays. Apoptosis increased in a time-dependent manner (Figure 2a). In H157 cells, the combination increased apoptosis over either drug alone, which was most evident at $48 \mathrm{~h}$. In RPMI8226 cells, NFV and BZ were more effective as single agents. The combination was most effective at $24 \mathrm{~h}$ ( $P<0.001$; Figure 2a). To investigate the mechanism of cell death, caspase and PARP cleavage were assessed by immunoblotting (Figure 2b). The combination induced greater cleavage of caspases $8,9,3,7$, and PARP than either drug alone. Although some caspase 4 cleavage was noted with NFV or BZ treatment in $\mathrm{H} 157$ cells, this did not appear to be enhanced with the combination.

To determine if caspase activation is required for cell death, we used a pan-caspase inhibitor (Z-VAD), and measured apoptosis and total cell death (Figure 2c). The combination enhanced apoptosis compared with either drug alone $(P<0.001)$, and this was significantly attenuated with Z-VAD pre-treatment $(P<0.001$; Figure 2c, left). In addition, Z-VAD decreased total cell death ( $P<0.001$; Figure $2 \mathrm{c}$, right). Similar results were observed with RPMI8226 cells, where pretreatment with Z-VAD decreased apoptosis and total cell death
(Supplementary Figure 1). Collectively, these data suggest that NFV and BZ enhance caspase-dependent apoptosis. However, ZVAD did not completely rescue the cell death induced by the combination. Thus, cell death induced by NFV and BZ may involve non-apoptotic cell death, as well as caspase-dependent apoptotic cell death.

Combining NFV with BZ enhances cytosolic proteotoxicity. To assess if the combination enhances the accumulation of Ub-proteins, we performed immunoblotting in $\mathrm{H} 157$ and RPMI8226 cells (Figure 3a). The combination enhanced levels of Ub-proteins more than with either drug alone, indicating proteotoxic stress in the cytosol. Additionally, the effect of the combination on cytosolic proteotoxicity was reconfirmed by measuring protein levels of the HSP70 chaperone. As shown in Figure $3 \mathrm{~b}$, the combination enhanced HSP70 expression in H157 and RPMI8226 cells in a time-dependent manner. Collectively, these data suggest that NFV and BZ enhance cytosolic proteotoxicity.

Combining NFV with BZ enhances ER stress. To determine if the combination can induce UPR signaling, immunoblotting was performed at different time points (Figure 4a). In H157 cells, expression of BiP and phosphorylation of double-stranded RNA activated protein kinase-like endoplasmic reticulum kinase (PERK), inositol requiring-1 (IRE1), and elF2 $\alpha$ increased by $8 \mathrm{~h}$. Activating transcription factor (ATF)3, CCAAT-enhancer binding protein homologous protein (CHOP), and spliced X-box-binding protein 1 $\left(\mathrm{XBP}-1^{\mathrm{s}}\right)$ also increased more with the combination than with either drug alone, and this was evident by $8 \mathrm{~h}$. Other markers were less affected. In RPMI8226 cells, the combination enhanced elF2 $\alpha$ phosphorylation, as well as expression of $\mathrm{BiP}, \mathrm{ATF} 3$, and $\mathrm{CHOP}$, and this was most evident at $24 \mathrm{~h}$. These data show that NFV and BZ enhance UPR in a time-specific manner in two independent cell lines.

$\mathrm{CHOP}$ is a major mediator of ER stress-induced apoptosis, and is induced by the three major UPR signaling pathways via activation of PERK, ATF6, or IRE1. PERK is a major upstream mediator of $\mathrm{CHOP}$ induction, ${ }^{16}$ but its phosphorylation was induced less than expression of CHOP in response to NFV and/or BZ (Figure 4a). To clarify the role of PERK in the cell death induced by the combination, PERK-deficient cells were employed (Figure 4b). Apoptosis caused by the combination was reduced by $57 \%$ in PERK $-/$ - MEFs $(P<0.001)$, suggesting that $P E R K$ is directly involved in apoptosis induced by the combination. Taken together, these data show that ER stress contributes to cell death induced by the combination of NFV and BZ.

Knockdown of ATF3 or CHOP expression inhibits cell death induced by the combination of NFV and BZ. To identify other components of the UPR that are required for

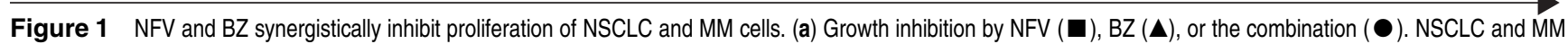
cells were treated with drugs at the indicated concentrations for 48 and $72 \mathrm{~h}$, respectively. Bars, S.D. (b) Cells were prepared and treated as described in (a). Computersimulated Fa-Cl curves display synergism $(\mathrm{Cl}<1)$, additive effect $(\mathrm{Cl}=1)$, or antagonism $(\mathrm{Cl}>1)$ for the entire spectrum of effect levels in the combination $($ see also Supplementary Table 1A, right). $\times$ Indicates the actual Fa-Cl plot based on experimental values (see also Supplementary Table 1A, left). (c) Growth inhibition of BZ-resistant MM cell lines. RPMI8226 V10R and Kas-6 V10R cells were treated with either $8 \mu \mathrm{M} \mathrm{NFV,} \mathrm{BZ} \mathrm{at} \mathrm{the} \mathrm{indicated} \mathrm{concentrations,} \mathrm{or} \mathrm{the} \mathrm{combination} \mathrm{for} 72 \mathrm{~h}$, respectively. Bars, S.D. (d) Cells were prepared and treated as described in (c). $\times$ Indicates the actual Fa-Cl plot based on experimental values (see also Supplementary Table 1B) 
a
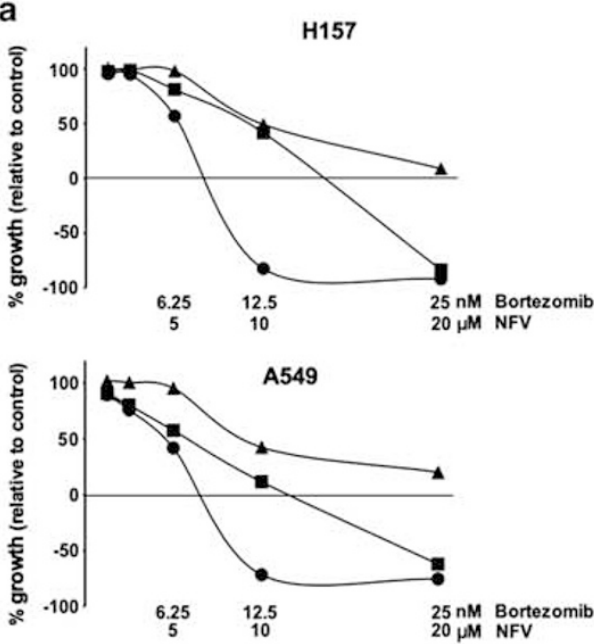

b
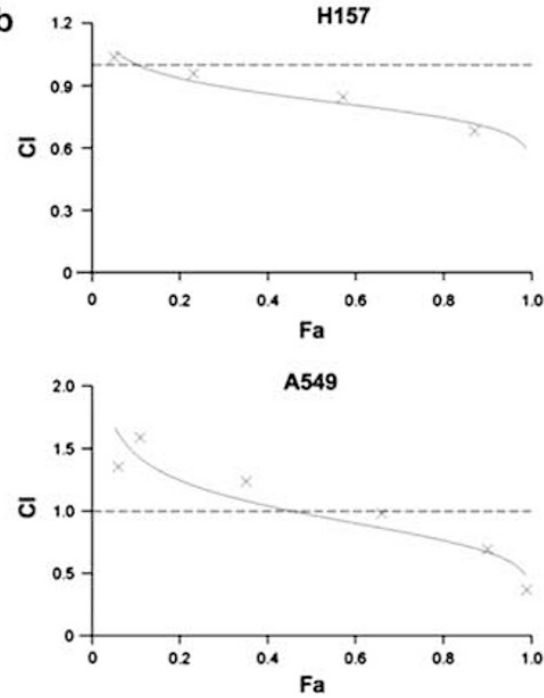

C

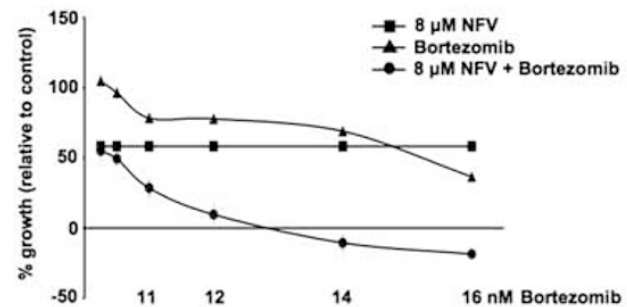

d

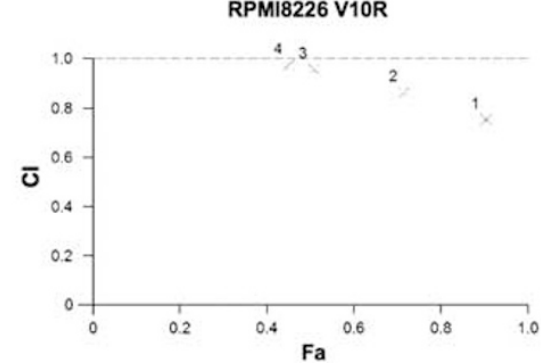

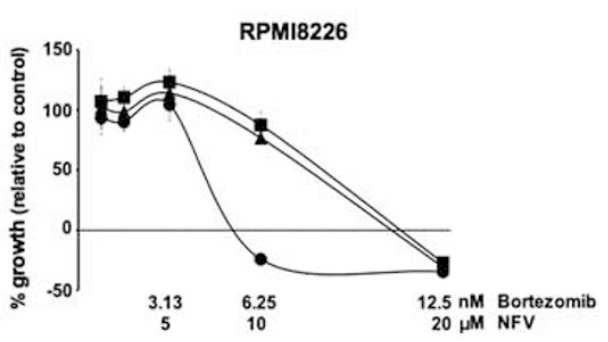
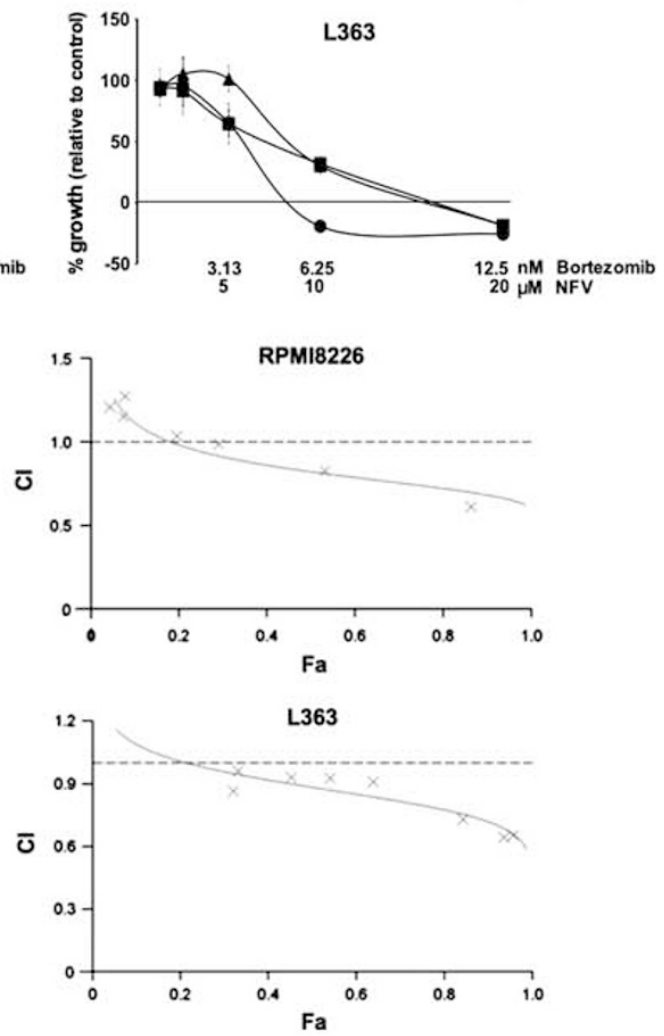

Kas-6 V10R

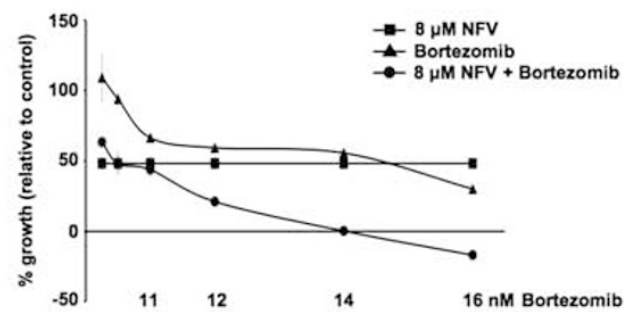

Kas-6 V10R

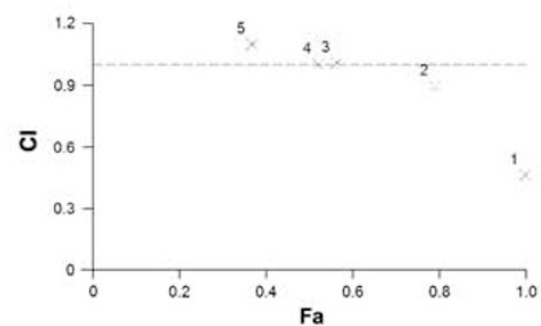


a
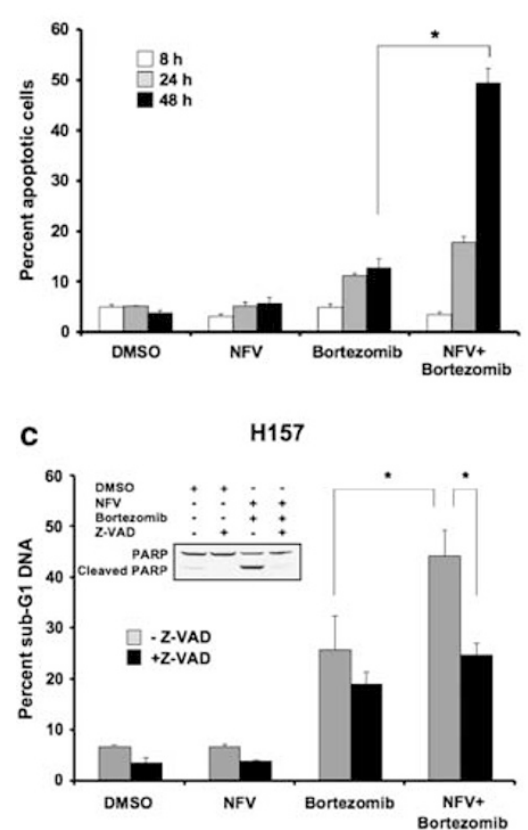

RPMI8226

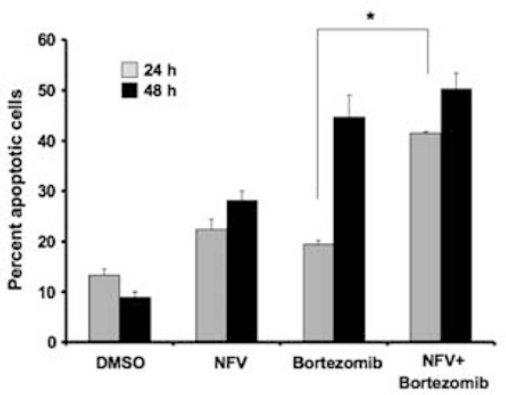

H157

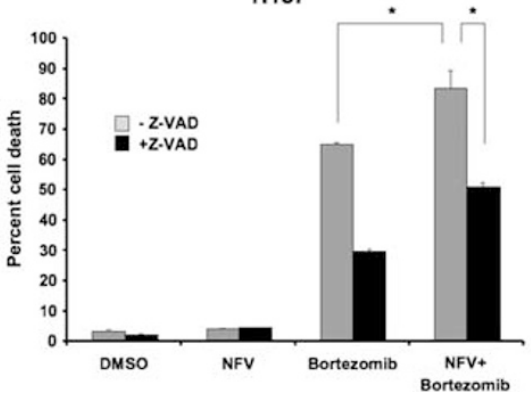

b

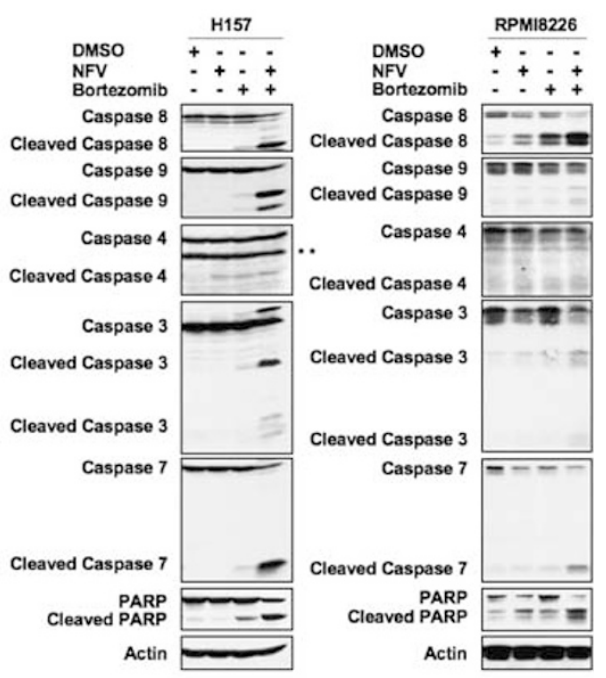

Figure 2 Combining NFV with BZ enhances caspase-dependent apoptosis. (a) Enhancement of apoptosis. H157 cells were treated with either DMSO, $10 \mu \mathrm{M}$ NFV, $12.5 \mathrm{nM} \mathrm{BZ}$, or the combination for the indicated times, and RPMI8226 cells were treated with either DMSO, $10 \mu \mathrm{M} \mathrm{NFV}, 6.25 \mathrm{nM}$ BZ, or the combination for the indicated times. Cells were harvested and analyzed by Annexin V binding assays. (b) Induction of caspase and PARP cleavage. H157 and RPMI8226 cells were treated with the drugs at the concentration as described in (a) for 48 and $24 \mathrm{~h}$, respectively. Levels of the indicated markers were assessed by immunoblotting. ${ }^{* *}$ Non-specific band. (c) Enhancement of caspase-dependent apoptosis. H157 cells were pre-treated or not with $50 \mu \mathrm{M}$ Z-VAD for $1 \mathrm{~h}$, followed by treatment with either DMSO, $10 \mu \mathrm{M} \mathrm{NFV}, 12.5 \mathrm{nM}$ BZ, or the combination for $48 \mathrm{~h}$. Cells were harvested and analyzed by DNA fragmentation and cell death assays. PARP cleavage was assessed by immunoblotting to confirm inhibition of caspases by Z-VAD. Columns, mean from at least three separate experiments; bars, S.D. ${ }^{*} P<0.001$
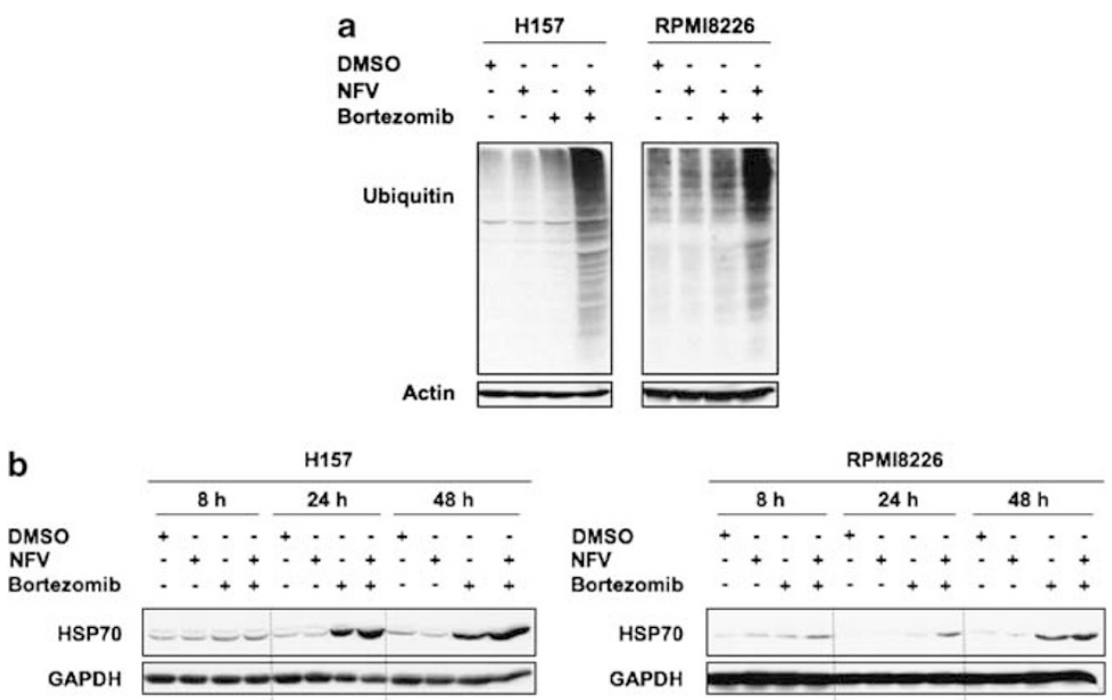

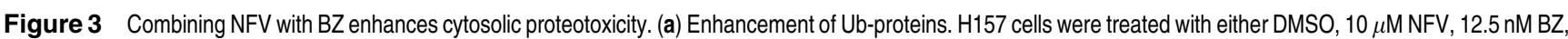
or the combination for $48 \mathrm{~h}$, and RPMI8226 cells were treated with either DMSO, $10 \mu \mathrm{M} \mathrm{NFV,} 6.25 \mathrm{nM} \mathrm{BZ}$, or the combination for $48 \mathrm{~h}$. Immunoblotting was performed. (b) Increase of HSP70 indicates the existence of proteotoxic stress in the cytosol. Cells were treated with the drugs at the concentration as described in (a) for the indicated time. Level of HSP70 was assessed by immunoblotting

cell death induced by NFV and BZ, H157 and RPMI8226 cells were transfected with small interfering RNA (siRNA) to ATF3, DDIT3 (encoding CHOP), or non-targeting control SiRNA, and then treated with the combination or vehicle. ATF3 siRNA suppressed ATF3 expression and inhibited cell death induced by the combination in H157 and in RPMI8226 cells $(P<0.01$ and $P<0.001$, respectively; Figure 4c). Similarly, CHOP (DDIT3) siRNA suppressed CHOP expression and decreased cell death in response to the combination (Figure 4d). Taken together, these data suggest that ATF3 and $\mathrm{CHOP}$ have a role in cell death induced by the combination. 
CHOP can mediate ER stress-induced apoptosis through multiple mechanisms, including suppression of the antiapoptotic protein Bcl-2, ${ }^{4,17}$ and transcriptional induction of the death receptor DR5. ${ }^{18}$ As NFV and BZ induced CHOP expression and caused CHOP-dependent death, the expression of Bcl-2 and death receptors was assessed. At $24 \mathrm{~h}$, the combination decreased $\mathrm{Bcl}-2$ expression and enhanced DR5 and DR4 expression in $\mathrm{H} 157$ cells (Supplementary Figure 2). Bax, Fas, and $\mathrm{Mcl}-1$ expressions were not affected. These data suggest that the regulation of $\mathrm{Bcl}-2$ and death receptors by $\mathrm{CHOP}$ might be involved in death induced by NFV and BZ. As NFV is known to decrease Akt phosphorylation, ${ }^{15}$ signaling pathways involved in cell proliferation were assessed. The combination of NFV and BZ activated stress kinases, JNK and p38, but not Akt and p44/42 (ERK) kinases involved in many cellular programs, such as cell proliferation (Supplementary Figure 3).

Proteotoxic stress is required for cell death induced by the combination of NFV and BZ. To demonstrate that proteotoxic stress caused by NFV and BZ originates during the synthesis of new proteins, cycloheximide $(\mathrm{CHX})$ was used to inhibit protein synthesis. Treatment of $\mathrm{H} 157$ cells with $\mathrm{CHX}$ inhibited cytoplasmic vacuolization caused by NFV-induced dilatation of $\mathrm{ER}^{15}$ (Figure 5a). This data suggests that inhibition of protein synthesis decreased the load of misfolded proteins. Moreover, $\mathrm{CHX}$ prevented the accumulation of Ub-proteins and induction of HSP70, ATF3, and $\mathrm{CHOP}$ in $\mathrm{H} 157$ and RPMI8226 cell lines, suggesting a decrease in proteotoxic stress (Figure 5b). Additionally, $\mathrm{CHX}$ significantly blocked total cell death induced by the combination in NSCLC and MM cells (Figure $5 \mathrm{c}$ ). Taken together, these findings suggest that proteotoxic stress is important for the synergistic effect of the combination, and that basal levels of protein synthesis may predict for response to NFV and $\mathrm{BZ}$.

Combining NFV with BZ inhibits NSCLC and MM tumor growth in vivo. To determine if the combination of NFV and $\mathrm{BZ}$ has enhanced anti-tumor effects, athymic NCr-nu/nu mice bearing established $\mathrm{H} 157$ or RPMI8226 tumor xenografts were treated with $50 \mathrm{mg} / \mathrm{kg} \mathrm{NFV}, 0.5 \mathrm{mg} / \mathrm{kg} \mathrm{BZ}$, or the combination. The combination of NFV and BZ was well tolerated, and decreased $\mathrm{H} 157$ tumor growth by nearly $70 \%$ (Figure 6a, upper) and RPMI8226 tumor growth by nearly $85 \%$ (Figure $6 \mathrm{a}$, lower, and Figure $6 \mathrm{~b}$ ) compared with vehicle-treated mice. To correlate anti-tumor effects with mechanisms identified in vitro, markers of ER stress and apoptosis were assessed in the tumors. The combination increased expression of Bip, CHOP, XBP-1 ${ }^{\text {s }}$, Ubiquitin, HSP70, and cleaved caspase 3 and PARP compared with control (Kruskal-Wallis test $P<0.05$ ) in $\mathrm{H} 157$ xenograft tumors (Figure 6c, and Supplementary Figures 4A and B), suggesting that the combination of NFV and BZ inhibited the growth of $\mathrm{H} 157$ tumors, which correlated with the induction of markers of ER stress and apoptosis. Additionally, CHOP was increased by the combination of NFV and BZ in RPMI8226 xenograft tumors (Supplementary Figure 4C). In H157 and RPMI8226 xenograft tumors, the staining for the nuclearspecific antigen $\mathrm{Ki}-67$ revealed a significantly lower rate of proliferation in the combination-treated tumors compared with vehicle-treated counterparts (Figure 6d). These data suggest that the combination inhibits NSCLC and MM tumor growth, and increases ER stress-induced apoptosis in vivo.

\section{Discussion}

The proteotoxic effects of combining NFV with $\mathrm{BZ}$ are consistent with the following mechanism (Figure 7). NFV and $\mathrm{BZ}$ can each induce ER stress, whereas the combination further enhances ATF3 and CHOP expression to cause cell death. In addition, NFV-induced ER stress triggers ERAD to cause accumulation of Ub-proteins that are typically degraded by UPS. As BZ inhibits the UPS, cells accumulate Ub-proteins through ERAD, but are incapable of degrading them via UPS, which results in cytosolic proteotoxicity. Simply put, NFV enhances cellular dependence on the proteasome, which could be exploited for cancer therapy.

If proteotoxic stress in the cytosol exceeds the capacity of the UPS to Ub-proteins, autophagy can compensate for protein degradation and contribute to cell survival. ${ }^{19}$ However, sustained autophagy finally leads to non-apoptotic cell death. As NFV and BZ have been reported to induce autophagy, immunoblotting for LC3, a maker of autophagy, was performed. The expression of LC-3 II was increased by either NFV or BZ alone. This observation was increased more by the combination, suggesting enhanced autophagy (Supplementary Figure 5). These data suggest that combining NFV with BZ may sustain autophagy, resulting in autophagic cell death.

Disruption of protein homeostasis was first validated as a therapeutic approach for cancer by the success of BZ in MM. $B Z$ now has several indications in $\mathrm{MM}$ and mantle cell lymphoma, but many patients do not initially respond and the majority of those that do respond eventually relapse. BZ has also shown efficacy in preclinical models of solid tumors; however, clinical trials have so far been disappointing. ${ }^{20}$ Proteotoxic therapies may have particular efficacy in tumors that have high rates of protein synthesis, such as those that produce secretory proteins, including thyroid, breast, pancreatic and prostate cancer, carcinoid, and B-cell malignancies. In this study, the combination of NFV and BZ synergistically decreased proliferation and induced death in BZ-sensitive and -resistant MM cell lines (Figure 1 and Supplementary Table 1). BZ resistance has been associated with multiple mechanisms, including overexpression of HSP90, HSP27, proteasome subunits, and Bcl-2. ${ }^{21-23}$ In our study, the combination of NFV and BZ increased ATF3 and decreased bcl-2 expression (Figure $4 \mathrm{a}$ and Supplementary Figure 2). Bruning et al. ${ }^{24}$ reported that NFV and BZ increased the expressions of Bip and ATF3 in cervical cancer cell lines, supporting the results presented here. ATF3 levels have been associated with sensitivity to BZ-induced apoptosis, ${ }^{21}$ thus our data suggests that NFV may overcome resistance to BZbased regimens in MM patients.

In addition to MM cells, we chose to investigate this combination in NSCLC, because our previous work showed that NFV induced proteotoxicity in NSCLC xenografts and cell lines, ${ }^{15}$ and $\mathrm{BZ}$ has had only modest clinical activity in NSCLC. For example, a Phase II study combining BZ with a 
platinum/gemcitabine doublet in patients with advanced NSCLC recently showed a response rate of $23 \%$ and a median survival of 11 months, which is what one would expect

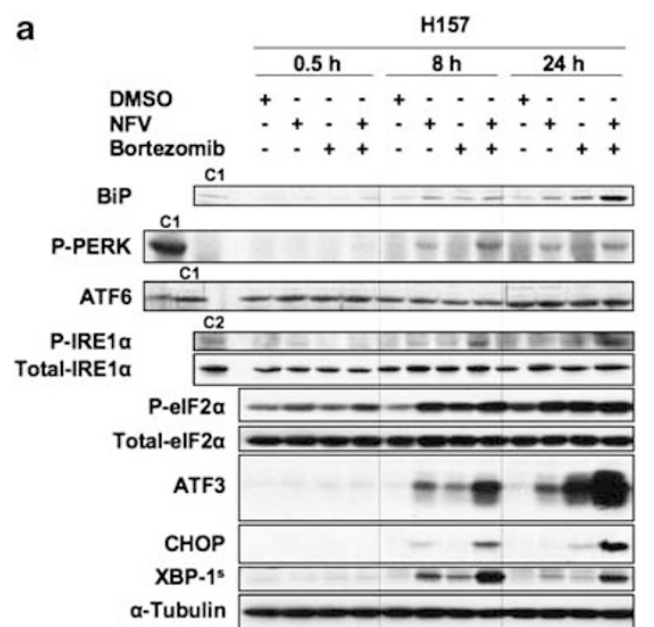

with the platinum doublet alone. ${ }^{25}$ As a single agent, BZ has minimal activity in EGFR tyrosine kinase inhibitor-resistant lung cancer. ${ }^{26,27}$ Together, these reports suggest that
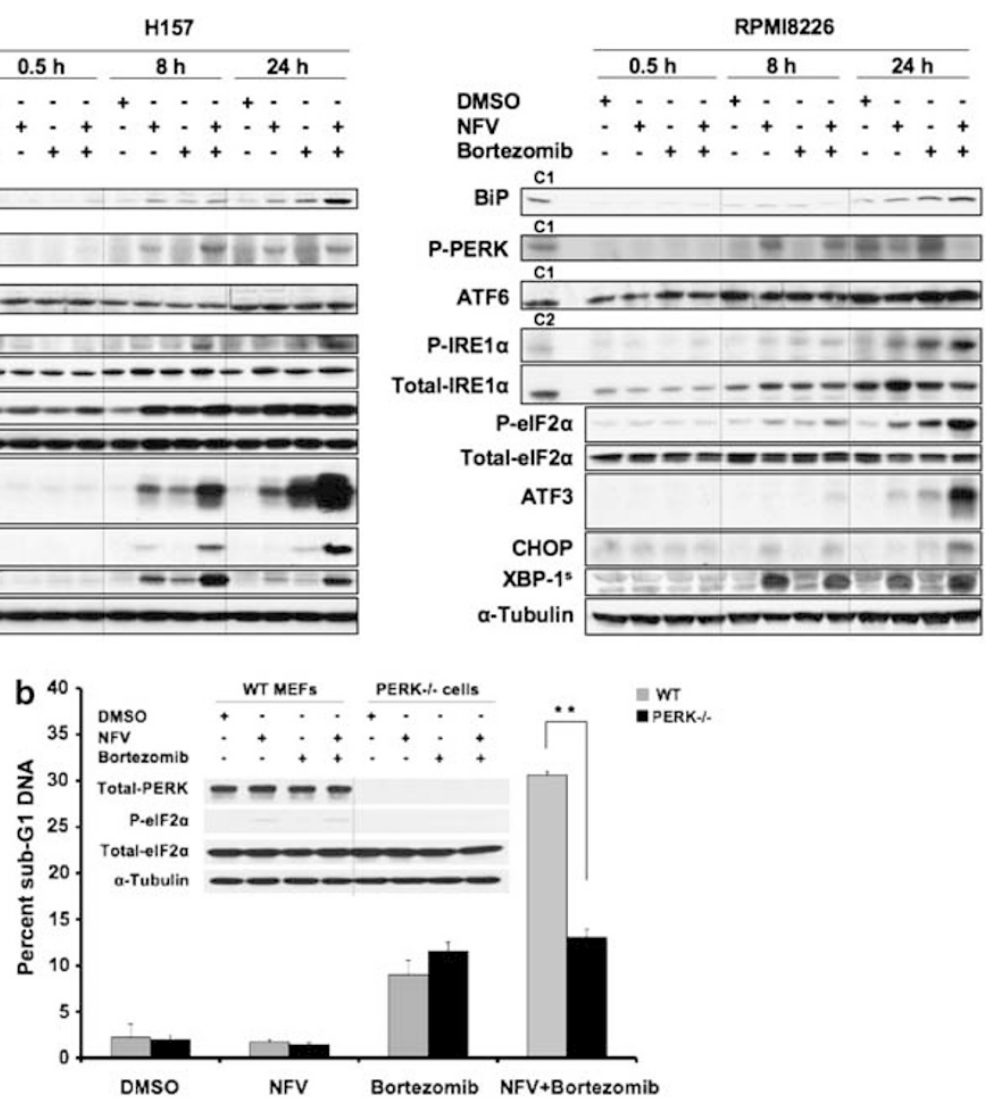

C H157

RPMI8226
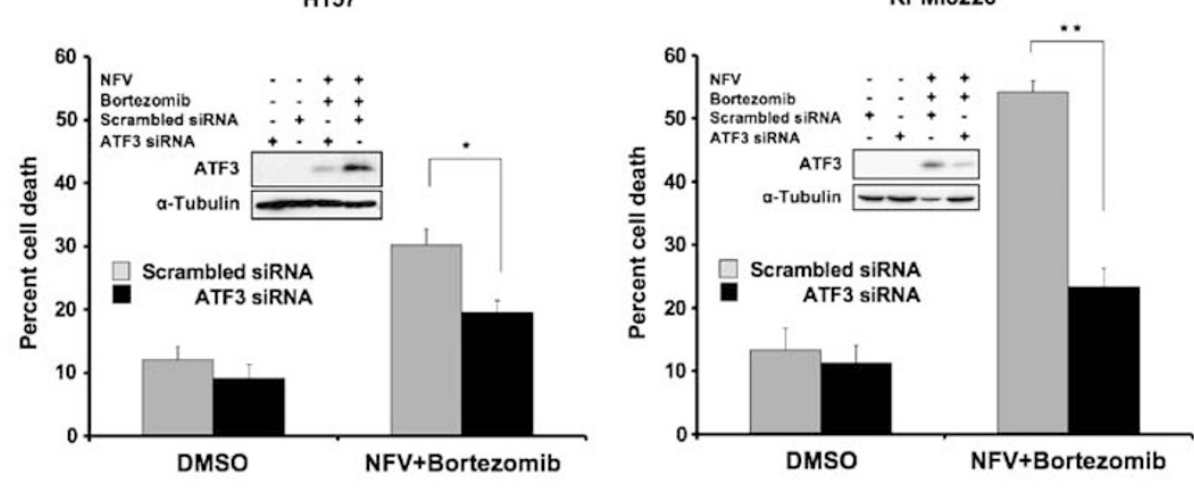

d

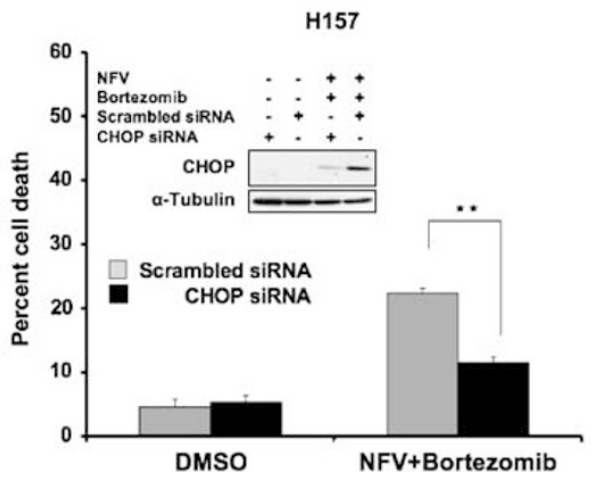

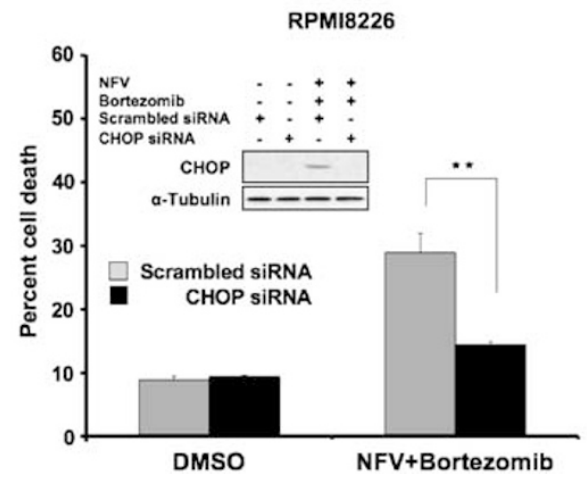


combining NFV with BZ might be an effective approach for NSCLC through enhanced proteotoxicity, which is supported by studies that show that a combination of gefitinib with a celecoxib analog induced CHOP and cell death in NSCLC cells. ${ }^{28}$

In this study, the combination of NFV and BZ synergistically increased markers of ER stress and Ub-proteins in the cytosol of NSCLC and MM cells. Ritonavir, another HIV PI with structural similarity to NFV, can also enhance Ub-proteins in sarcoma cells when combined with $B Z,{ }^{29}$ supporting the results presented here. Mechanisms whereby Ub-proteins become cytotoxic have been previously investigated. Nawrocki et al. ${ }^{11}$ reported that combining BZ with an HDAC inhibitor prevented lysosomal proteolysis of Ub-proteins in the cytosol and increased ER dilation, indicating a relationship between cytosolic proteotoxicity and ER stress. Mimnaugh et al. ${ }^{9}$ reported that Ub-proteins might influence ERAD. Valosin-containing protein (VCP), a member of the AAAATPase super family, binds to Ub-proteins through ERAD and leads to their proteasomal degradation. They suggested that the redistribution of VCP from the ER and cytosol into aggresome-like bodies leads to ERAD failure, resulting in enhancing ER stress. Taken together, these reports suggest that Ub-proteins might cause cytotoxic effects by enhancing ER stress.

The UPR may be cytoprotective, or in cases where protein misfolding and ER stress are not relieved, it can also contribute to apoptosis. Some tumors rely on constitutively active UPR signaling to survive in hostile environments. ${ }^{30}$ Here, cell death induced by the combination of NFV and BZ relied on PERK, ATF3, and CHOP induction. Wang et al. ${ }^{12}$ reported that $A T F 3$ is required for transcriptional activation of the pro-apoptotic $\mathrm{BH} 3-$ only gene, NOXA, by $\mathrm{BZ}$, suggesting that ATF3-regulated NOXA may contribute to the cytotoxicity of NFV and BZ as an intrinsic apoptotic pathway. On the other hand, Taketani et al. ${ }^{31}$ reported that ATF3 is required for efficient DR5 induction upon DNA damage by camptothecin, suggesting that ATF3-related DR5 may be involved in the induction of extrinsic apoptosis by the combination of NFV and $B Z$. In addition, the combination increased expression of the death receptors DR4 and DR5, and decreased expression of $\mathrm{Bcl}-2$ (Supplementary Figure 2), which is consistent with the data of Tian et al., ${ }^{32}$ who showed that NFV could induce CHOP and ATF4-dependent DR5 expression in glioma cell lines.

In summary, the combination increased apoptotic and total cell death in MM and NSCLC cells through increased cytosolic proteotoxicity and ER stress. Induction of proteotoxicity is a promising new target for cancer therapy. Combining NFV with $B Z$, both FDA-approved agents, may be a novel way to overcome BZ resistance in MM. Furthermore, this combination may expand clinical indications for proteasome inhibitors, and make therapeutic inroads in cancers that are difficult to treat, such as NSCLC.

\section{Materials and Methods}

Cell cultures. NSCLC ( $\mathrm{H} 157$ and A549) cell lines were obtained as described previously. ${ }^{15} \mathrm{MM}$ (RPMI8226 and L363) cell lines were kind gifts from Dr. W Michael Kuehl (National Cancer Institute, Bethesda, MD, USA). BZ-resistant and parental MM (RPMI8226 V10R and RPMI8226, Kas-6 V10R and Kas-6) cell lines were kind gifts from Dr. Robert Z Orlowski (The University of Texas M.D. Anderson Cancer Center, Houston, TX, USA). Immortalized PERK - I - MEFs were gifts from Dr. David Ron (University of Cambridge, Cambridge, UK). These cells were maintained as described previously. ${ }^{15,33,34}$ In addition, both RPMI8226 V10R and Kas-6 V10R cells were cultured in media supplemented with $10 \mathrm{nM} \mathrm{BZ}$.

Reagents. NFV used in the in vitro studies was obtained through the NIH AIDS Research and Reference Reagent Program, Division of AIDS, NIAID, NIH. NFV used in the in vivo study was obtained from Pfizer Inc. (New York, NY, USA). BZ was purchased from Millennium Pharmaceuticals, Inc. (Cambridge, MA, USA). Z-VAD-FMK was obtained from Biomol (Plymouth Meeting, PA, USA). Tunicamycin and $\mathrm{CHX}$ were obtained from Sigma (St. Louis, MO, USA). Primary antibodies for cleaved/total caspase 3, 7, 8, 9, cleaved/total PARP, Ubiquitin, HSP70, GAPDH, BiP, IRE1 $\alpha$, P-elF2 $\alpha$ (Ser51, 119A11, 1:500), elF2 $\alpha$, P-JNK (Thr183/Tyr185), P-p38 (Thr180/Tyr182), p38, P-Akt (Ser473), P-Akt (Thr308), Akt, P-p44/42 (Thr202/Tyr204) (E10), p44/42, Bcl-2, Bax, and Mcl-1 were from Cell Signaling Technology (Beverly, MA, USA). Antibodies for cleaved/total caspase 4 (N-15), P-PERK (Thr981, 1:200), ATF3 (C-19), CHOP/GADD153 (B-3, 1:500), Fas (C-20), and DR4 ( $\mathrm{H}-130)$ were from Santa Cruz Biotechnology (Santa Cruz, CA, USA). Anti-Actin (JLA20) and $\alpha$-Tubulin antibodies were from Calbiochem (EMD Chemicals Inc., Gibbstown, NJ, USA) and Sigma, respectively. Anti-LC-3 (2G6, $1: 200)$ antibody was from nanoTools (Teningen, Germany). AntiATF6 (70B1413.1, 1:200) antibody was from Imgenex (San Diego, CA, USA). Anti-P-IRE1 $\alpha$ (Ser724, ab48187, 1:500) and DR5 antibodies were from Abcam (Cambridge, MA, USA). Anti-XBP-1 ${ }^{\mathrm{s}}$ (Poly6195, 1:500) antibody was from BioLegend (San Diego, CA, USA).

Cell proliferation assay. NSCLC cells (2500 cells per well) and MM cells (5000 cells per well) were plated in 96-well plates and allowed to grow overnight. Either NFV dissolved in DMSO, BZ dissolved in PBS, or the combination was added, and the cells were allowed to grow for an additional 48 or $72 \mathrm{~h}$. NFV and BZ were administrated simultaneously, based on preliminary data that the concurrent schedule showed similar effect to the sequential schedule (NFV followed by additional BZ treatment) in Supplementary Figure 6. For adherent NSCLC cells, growth inhibition was determined by the sulforhodamine B assay. ${ }^{35}$ For non-adherent MM cells, WST1 reagent was added to the plates according to the manufacturer's protocol (Roche Diagnostics, Indianapolis, IN, USA). Percent growth value was calculated by using the absorbance values of untreated cells on day 0 (D0), DMSO-treated control cells (C), and drug-treated cells (T) as follows: $[(T-D 0) /(C-D 0)] \times 100$ for concentrations for which $T \geq D 0$, or $[(T-D 0) /$ $\mathrm{C}] \times 100$ for concentrations for which $\mathrm{T}<\mathrm{D} 0$. Percent growth curve was generated on the basis of the \% growth values in a dose-dependent manner. Experiments were performed in triplicate, and each drug concentration was evaluated in sextuplet wells for any given experiment. $\mathrm{Cl}$ is a quantitative measure of the degree of drug interaction in terms of synergism $(\mathrm{Cl}<1)$, additive effect $(\mathrm{Cl}=1)$, or antagonism $(\mathrm{Cl}>1)$ for a given endpoint of the effect measurement. ${ }^{36}$

Figure 4 Combining NFV with BZ enhances ER stress, and ATF3 or CHOP silencing inhibits the combination-induced cell death. (a) Enhancement of ER stress. H157 cells were treated with either DMSO, $10 \mu \mathrm{M} \mathrm{NFV}, 12.5 \mathrm{nM} \mathrm{BZ}$, or the combination for the indicated times, and RPMI8226 cells were treated with either DMSO, $10 \mu \mathrm{M}$ NFV, $6.25 \mathrm{nM} \mathrm{BZ}$, or the combination for the indicated times. Immunoblotting was performed for ER stress markers. C1 and C2 are controls that are $\mathrm{H} 157$ cell lysates treated with $6 \mu \mathrm{M}$ Tunicamycin for 24 and $8 \mathrm{~h}$, respectively. (b) PERK is involved in the combination-induced apoptosis. PERK - / - and WT MEFs were treated with either DMSO, $10 \mu \mathrm{M}$ NFV, $12.5 \mathrm{nM} \mathrm{BZ}$, or the combination for $24 \mathrm{~h}$. Cells were harvested and analyzed by DNA fragmentation assays. Level of elF2 $\alpha$ (Ser51) phosphorylation was assessed by immunoblotting for evaluating PERK-deficiency in PERK - / - MEFs. (c and d) siRNA-mediated knockdown of ATF3 or CHOP inhibits the combination-induced cell death. Cells were pre-treated with either siRNA as described in Materials and Methods, and then $\mathrm{H} 157$ cells were treated with DMSO or the combination of $10 \mu \mathrm{M}$ NFV and $12.5 \mathrm{nM}$ $\mathrm{BZ}$ for $24 \mathrm{~h}$ (c) and for $17 \mathrm{~h}$ (d), and RPMI8226 cells were treated with DMSO or the combination of $10 \mu \mathrm{M} \mathrm{NFV}$ and $6.25 \mathrm{nM} \mathrm{BZ}$ for $24 \mathrm{~h}$ (c and d). Cells were harvested and analyzed by cell death assays. Columns, mean from at least three separate experiments; bars, S.D. ${ }^{*} P<0.01,{ }^{* *} P<0.001$ 
a
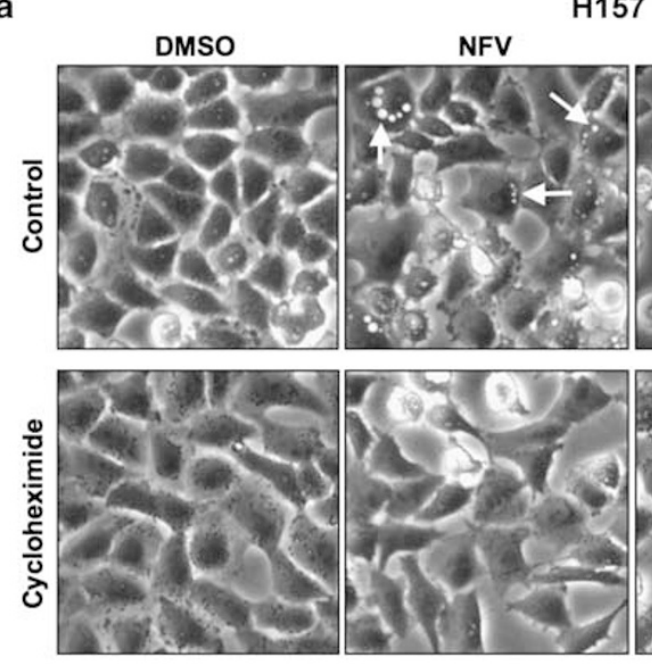

b
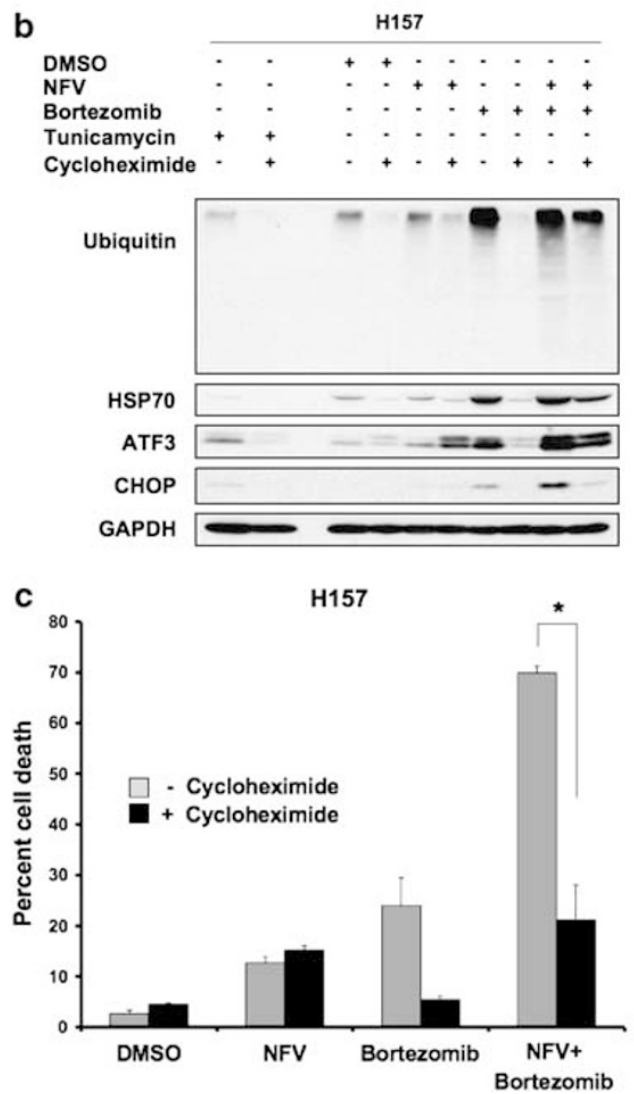

H157
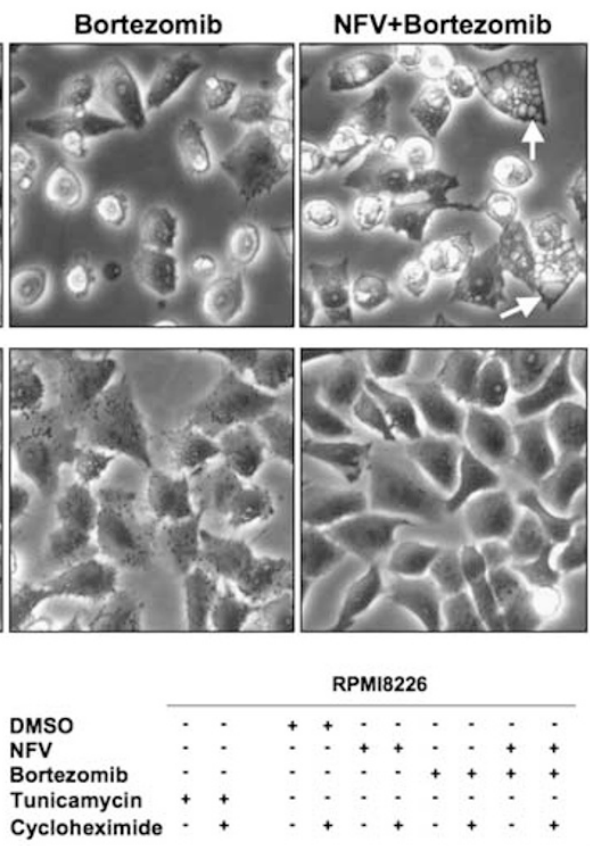

Cycloheximide *

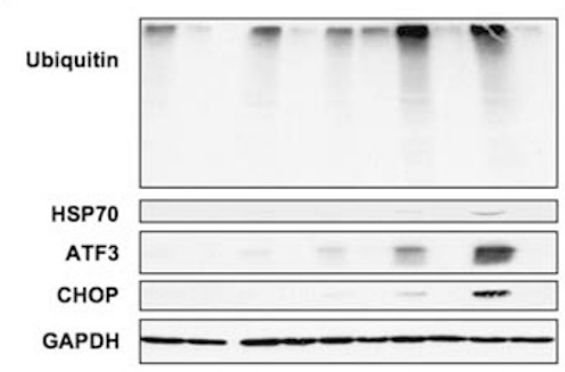

RPMI8226

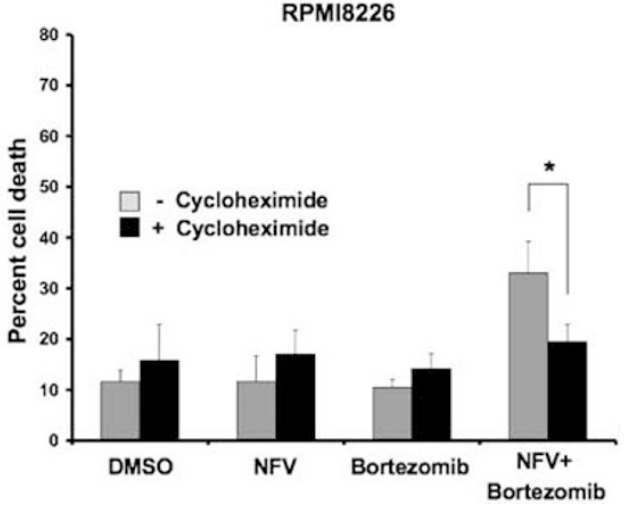

Figure 5 Proteotoxic stress is required for cell death induced by the combination of NFV and BZ. H157 cells were pre-treated or not with $1 \mu \mathrm{g} / \mathrm{ml}(3.6 \mu \mathrm{M}) \mathrm{CHX}$ for $3 \mathrm{~h}$, followed by treatment with either DMSO, $10 \mu \mathrm{M} \mathrm{NFV}, 12.5 \mathrm{nM} \mathrm{BZ}$, the combination, or $6 \mu \mathrm{M}$ Tunicamycin as a control for $48 \mathrm{~h}$. RPMl8226 cells were pre-treated or not with $0.1 \mu \mathrm{g} / \mathrm{ml}(0.36 \mu \mathrm{M}) \mathrm{CHX}$ for $3 \mathrm{~h}$, followed by treatment with either DMSO, $10 \mu \mathrm{M} \mathrm{NFV}, 6.25 \mathrm{nM} \mathrm{BZ}$, the combination, or $6 \mu \mathrm{M}$ Tunicamycin as a control for $24 \mathrm{~h}$. (a) Inhibition of protein synthesis decreases vacuolization of cytoplasm in $\mathrm{H} 157$ cells. Optical microscope images were taken at $\times 300$ magnifications. Arrows, point to vacuolization. (b) Decrease of proteotoxic stress. The indicated markers were assessed by immunoblotting. (c) Decrease of total cell death by cycloheximide. Cell death assay with propidium iodide were performed. Columns, mean from at least three separate experiments; bars, S.D. ${ }^{*} P<0.001$

Additive effect is defined as the combined effect predicted by the mass-action law principle, synergism is as the production of a greater-than-expected additive effect, and antagonism is as the production of smaller-than-expected additive effect. Cls were calculated by using CalcuSyn software program (BIOSOFT, Cambridge, UK). Affected fraction (Fa) is defined as a function (e.g., inhibition) of effect level by a dose of drug. Fa values were calculated according to the program's instruction as follows: [(100 - \% growth value)/100], which indicated a growth inhibition value.

Annexin V binding assay. Cells $\left(2 \times 10^{5}\right.$ cells per well) were plated in $12-$ well plates and allowed to grow overnight. The following day, cells were treated with drug or equal volume of DMSO for the indicated times. Floating and adherent 
a

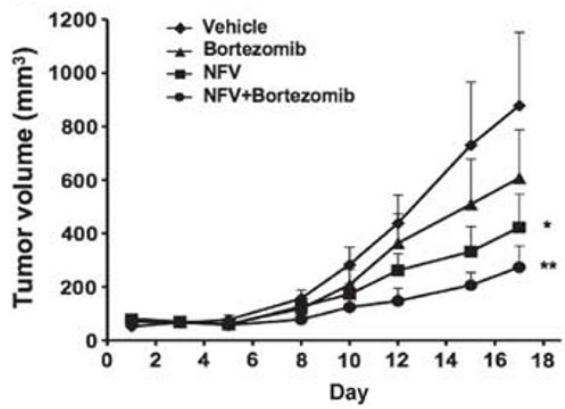

RPMI8226

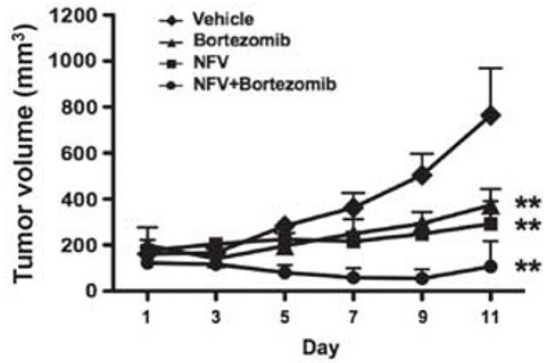

b
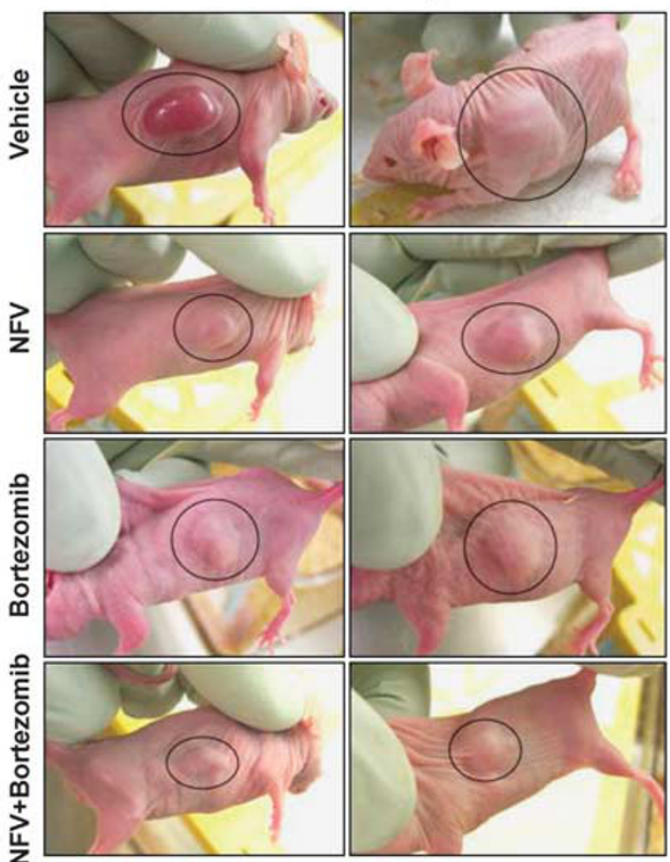

H157 tumor

C
P-elF2a

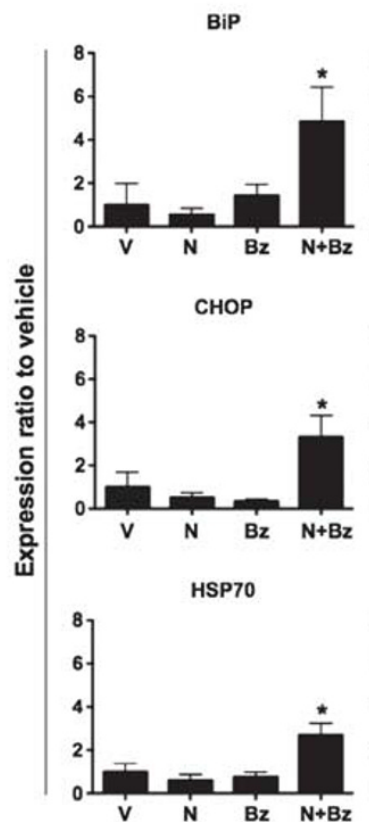

XBP-1s

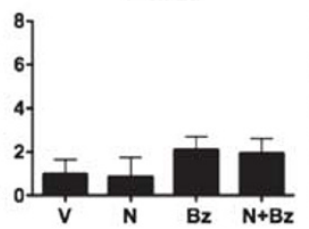

ATF3
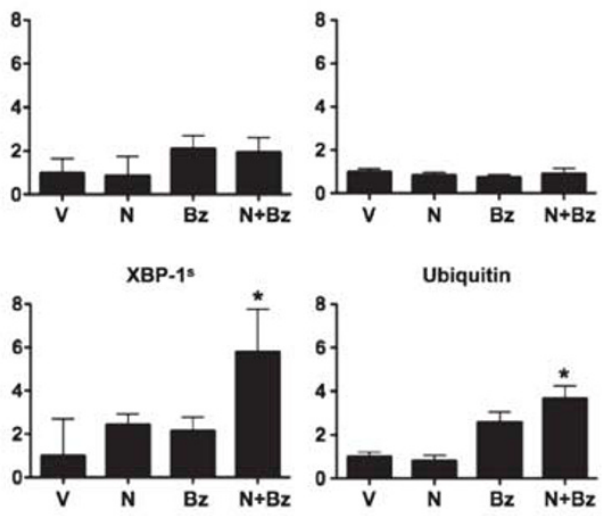

Cleaved Caspase 3

Cleaved PARP
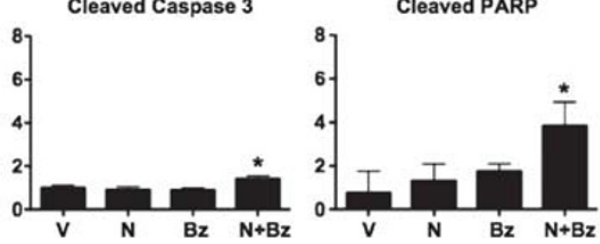

Figure 6 Combining NFV with BZ inhibits NSCLC and MM tumor growth in vivo. (a) H157 cells (upper) and RPMI8226 cells (lower) were grown as xenografts in athymic NCr-nu/nu. Bars, S.D. ${ }^{*} P<0.05$ for vehicle treatment, ${ }^{*} P<0.005$ for vehicle treatment. (b) Representative photos of RPMl8226 xenograft tumors of two different mice after 11 days of either treatment. Circles, RPMI8226 tumors. (c) ER stress, cytosolic proteotoxicity, and apoptosis markers in vivo. To examine the effect of the combination on biomarkers, $\mathrm{H} 157$ xenograft tumors after the 5 days of treatment as described in Materials and Methods were excised and prepared for the lysate. Levels of the indicated markers were assessed by immunoblotting. Densitometry was performed using NIH Image software, and levels of each marker were normalized to GAPDH for each sample; Columns, mean from all five mice examined. Bars, S.D. ${ }^{*} P<0.05$. (d) Inhibition of cell proliferation in H157 and RPMl8226 tumors. Levels of Ki67 were assessed by immunohistochemistry. The Ki67 staining index was achieved by assigning as described in Materials and Methods. Columns, mean from all five mice examined in $\mathrm{H} 157$ xenografts and from all three mice examined in RPMl8226 xenografts. Bars, S.D. ${ }^{*} P<0.05$

cells were harvested and resuspended in a solution of FITC-labeled Annexin V in Binding Buffer (BioSource, Camarillo, CA, USA) for $15 \mathrm{~min}$ at room temperature, stained with $1 \mu \mathrm{g} / \mathrm{ml}$ propidium iodide in PBS, and then immediately analyzed by a flow cytometer. FACScan analysis was performed using a Becton-
Dickinson FACSort and by manual gating using CellQuest software (FACSort, BD Biosciences, San Jose, CA, USA). Percent apoptotic cells were calculated as Annexin-V-FITC-positive cells for assessing early and late stages of apoptosis. 

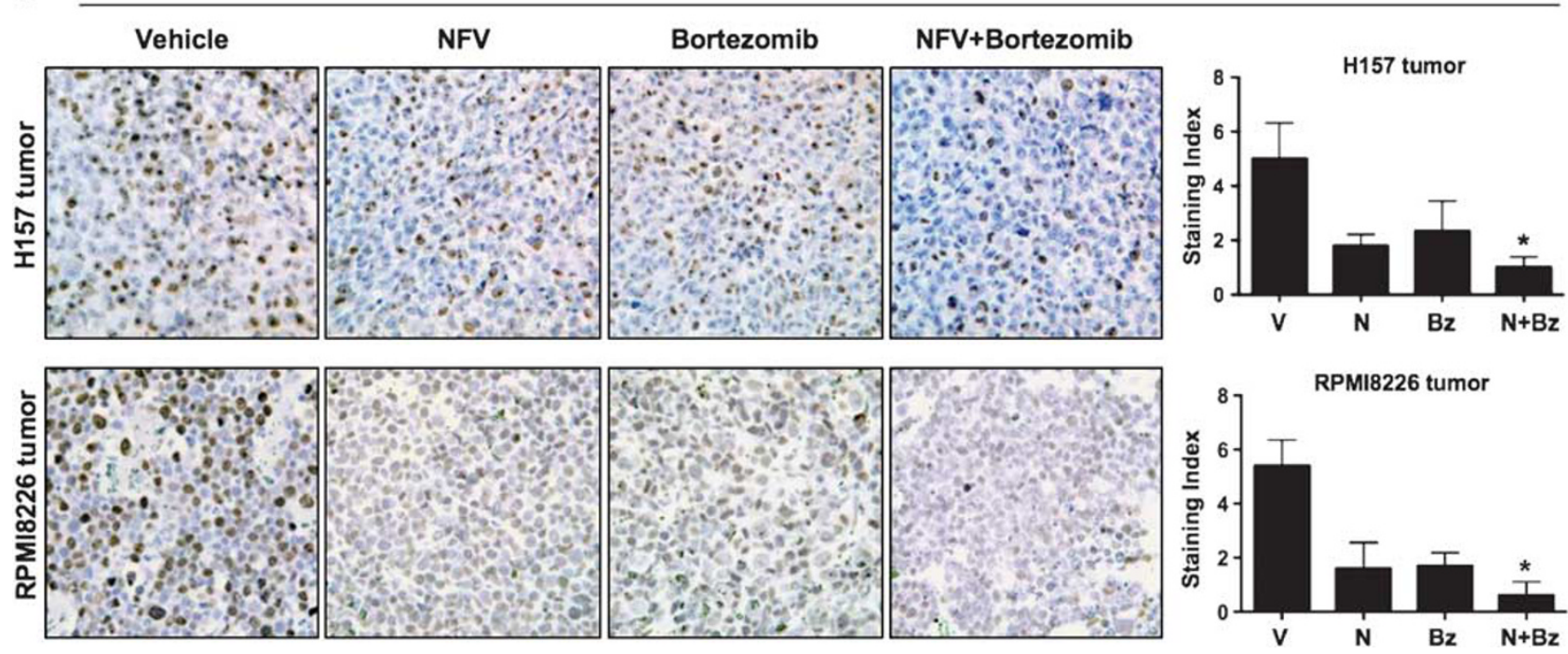

Figure 6 Continued

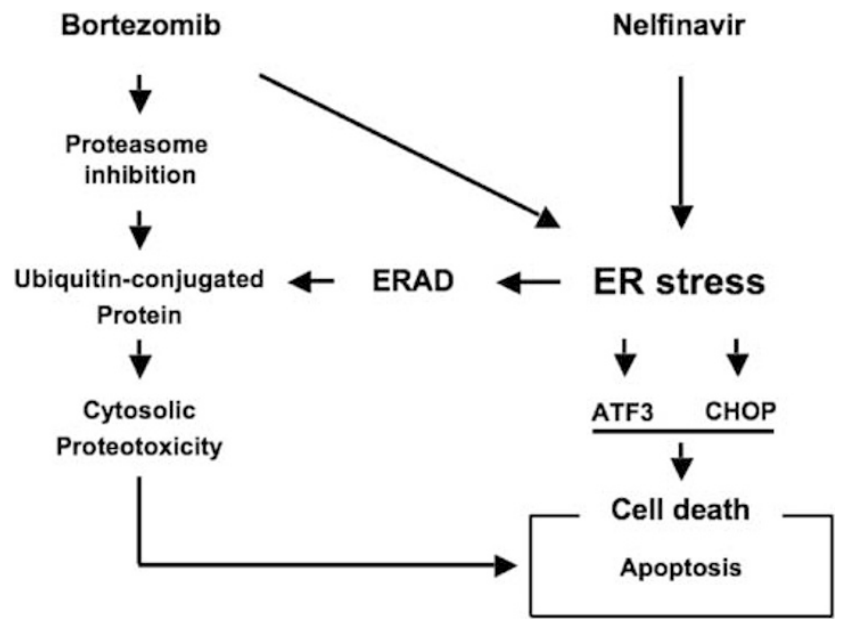

Figure 7 Proteototoxic mechanisms of the combination of NFV and BZ. Both $\mathrm{NFV}$ and $\mathrm{BZ}$ can induce ER stress, whereas the combination further enhances ATF3 and CHOP to result in cell death. In addition, NFV-induced ER stress triggers ERAD to accumulate Ub-proteins, which are typically degraded by UPS. As BZ inhibits UPS, the combination of NFV and BZ enhances the accumulation of Ubproteins through ERAD without degradation by UPS, resulting in cytosolic proteotoxicity

Immunoblotting. Cells $\left(5 \times 10^{5}\right.$ cells per well) were plated in six-well plates. The following day, cells were treated with drug or equal volume of DMSO for the indicated times, and lysed in $2 \times$ lysis buffer as described previously. ${ }^{15}$ For tumortissue homogenates in vivo, frozen tumors were allowed to thaw on ice, then homogenized in radioimmunoprecipitation assay buffer $(150 \mathrm{mmol} / \mathrm{l} \mathrm{NaCl}, 1 \%$ Igepal CA-630, 0.5\% sodium deoxycholate, $0.1 \%$ SDS, $50 \mathrm{mmol} / / \mathrm{Tris}$ (pH 8.0)) containing $2.5 \mathrm{~mol} / \mathrm{l}$ h-glycerol phosphate, $0.2 \mathrm{~mol} / /$ sodium orthovanadate, $1.25 \mathrm{~mol} / \mathrm{l}$ sodium fluoride, and $1 \times$ protease inhibitor cocktail (Roche Diagnostics) using a hand-held Tissue-Tearor homogenizer (Biospec Products, Bartlesville, OK, USA). Cell lysates or tumor-tissue homogenates with equal amounts of protein were separated by SDS-PAGE, then transferred to nitrocellulose membranes. The membranes were blocked for $1 \mathrm{~h}$ in blocking buffer $(1 \times$ TBS, $5 \%$ milk, $0.1 \%$ Tween 20) and placed in primary antibody diluted in $1 \times$ TBS, $5 \%$ bovine serum albumin (BSA), $0.1 \%$ Tween 20 , overnight at $4^{\circ} \mathrm{C}$ ). The following day, membranes were washed thrice in wash buffer $(0.1 \%$ Tween $20,1 \times$ TBS). Primary antibody was detected using horseradish-peroxidase-linked secondary antibodies, and visualized with the enhanced chemiluminescent detection system (Amersham Biosciences, Pittsburgh, PA, USA). Note that the membrane for PERK phosphorylation was blocked in blocking buffer with $5 \%$ BSA instead of $5 \%$ milk. Immunoblot experiments were performed at least three times.

DNA fragmentation assay. Cells $\left(2 \times 10^{5}\right.$ cells per well) were plated in $12-$ well plates and allowed to grow overnight. The following day, cells were treated with drug or equal volume of DMSO for the indicated times. Floating and adherent cells were harvested and fixed in cold $70 \%$ methanol. Following fixation, cells were stained with $25 \mu \mathrm{g} / \mathrm{ml}$ propidium iodide and $20 \mu \mathrm{g} / \mathrm{ml}$ RNase A in PBS for $30 \mathrm{~min}$ at room temperature. Quantification of sub-2N DNA was determined by flow cytometry using a Becton Dickinson FACSort and by manual gating using CellQuest software (FACSort, BD Biosciences). Apoptosis was calculated as the fraction of cells with sub-G1 DNA content. This assay is useful of evaluation of late apoptosis and necrotic cell death.

Cell death assay. Following incubation, floating cells were collected and adherent cells were harvested by trypsinization, and resuspended in a solution of $1 \mu \mathrm{g} / \mathrm{ml}$ propidium iodide in PBS, then immediately acquired on the FL3 channel of a flow cytometer. The propidium-iodide-positive population of cells was considered dead, whereas the propidium-iodide-negative population was considered viable.

siRNA-mediated gene silencing. Knockdown of ATF3 or CHOP expression was performed by transfection with human ATF3 Accell SMARTpool siRNA or human DDIT3 (encoding CHOP) Accell SMARTpool siRNA reagent (Thermo Scientific Dharmacon, Lafayette, CO, USA), respectively. Cells $\left(1 \times 10^{4}\right.$ cells per well) were plated in 24-well plates and allowed to grow overnight, and then were replaced with serum-free-Accell delivery media that included either $1 \mu \mathrm{M}$ ATF3 siRNA, $0.5 \mu \mathrm{M}$ DDIT3 siRNA, or $1 \mu \mathrm{M}$ non-targeting scrambled siRNA at $37^{\circ} \mathrm{C}$ in a $5 \% \mathrm{CO}_{2}$ for $48 \mathrm{~h}$. After transfection, cells were replaced with RPMI 1640 medium containing $5 \%$ FBS for $24 \mathrm{~h}$, and then were treated with drug or equal volume of DMSO. Gene-silencing effects were evaluated by immunoblotting.

Drug treatment in vivo. Six-week-old female athymic NCr-nu/nu mice (Charles River Labs, Frederick, MD, USA) were injected subcutaneously in both rear flanks with $5 \times 10^{6} \mathrm{H} 157$ cells in $100 \mu \mathrm{l}$ PBS. When the transplanted tumors reached a volume of $50 \mathrm{~mm}^{3}$, mice were divided into the following four groups (10 mice per group): intraperitoneal injection of either (1) vehicle (4\% DMSO, 5\% PEG, $5 \%$ Tween 80 in saline; once daily on days $1-5,8-12$, and $15-17$ ), (2) $50 \mathrm{mg} / \mathrm{kg} \mathrm{NFV} \mathrm{(once}$ daily on days $1-5,8-12$, and 15-17) as described previously, ${ }^{15}$ (3) $0.5 \mathrm{mg} / \mathrm{kg} \mathrm{BZ}$ 
(once daily on days $1,3,5,8,10,12,15$, and 17) on the basis of tolerated dosage as described previously, ${ }^{11}$ or (4) the combination of NFV and BZ (once daily on each drug's schedule). For studies with RPMI8226 cells, 6-week-old female athymic NCr-nu/nu mice were injected subcutaneously in both rear flanks with $1 \times 10^{7}$ RPMI8226 cells in $50 \mu \mathrm{l} \mathrm{PBS}$ and $50 \mu \mathrm{l} \mathrm{BD}$ Matrigel Basement Membrane Matrix (BD Biosciences). When the transplanted tumors reached a volume of $100 \mathrm{~mm}^{3}$, mice were divided into the four groups (five mice per group) and received either vehicle, $50 \mathrm{mg} / \mathrm{kg} \mathrm{NFV}, 0.5 \mathrm{mg} / \mathrm{kg} \mathrm{BZ}$, or the combination of NFV and $\mathrm{BZ}$ until days 11 , as well as studies with $\mathrm{H} 157$ cells. Animal weights and tumor measurements were made every other day. In all studies, tumor volume was calculated from the formula $v=\left(a b^{2}\right) / 2$, where $a$ is the long axis and $b$ is the short axis. To examine the effect of the combination on biomarkers, athymic $\mathrm{NCr}$-nu/nu mice bearing $\mathrm{H} 157$ or RPMI8226 tumor xenografts were administered vehicle, NFV, BZ, or the combination using the same doses described above. After the 5 days of treatment, the mice were killed and the tumors were harvested for analysis. In vivo experiments were conducted under a protocol approved by the $\mathrm{NCl}$ Animal Care and Use Committee.

Immunohistochemistry. Formalin-fixed, paraffin-embedded xenograft tumor tissues were sectioned, placed on poly-L-lysine-coated slides (Histoserv Inc., Germantown, MD, USA), and analyzed for protein expression for five mice per group. Antigen retrieval was carried out using preheated target retrieval solution ( $\mathrm{pH}$ 6.0) from DakoCytomation (Carpinteria, CA, USA) for $30 \mathrm{~min}$ in a boiling rice cooker. Vectastain Elite $A B C$ kits from Vector Laboratories (Burlingame, CA, USA) were used according to manufacturer's instructions for blocking, dilution of primary antibody, and labeling. For Ki67 (Abcam), the primary antibody was incubated with sections for $16 \mathrm{~h}$ at $4{ }^{\circ} \mathrm{C}$. 3,3-Diaminobenzidine was prepared fresh from tablets (Sigma). Specificity of staining was assessed by comparison with samples stained in the absence of primary antibody. All slides were blinded to the investigators before scoring, and in all cases, xenograft tumors were assessed for three to five mice per group. The Ki67 staining index was achieved by assigning a score of absent (0), minimal (1), moderate (2), or high (3) staining to each cell in five $\times 400$ magnification fields. The staining index was then calculated by multiplying the staining intensity by its distribution scored as 0 $(0 \%), 1(1-50 \%)$, and $2(51-100 \%)$ to indicate the percentage of positive cells of interest in a single core. An overall score was assigned to each slide, and the scores were averaged for vehicle versus drug-treated groups.

Statistics analysis. Statistical significance of differences observed in drugtreated and untreated cells was analyzed using two-factor ANOVA, and then multiple comparisons was performed by Bonferroni posttesting. All analyses were performed using the GraphPad Prism software version 5.0c (GraphPad Software, Inc., La Jolla, CA, USA). The threshold value was set to 0.05 .

\section{Conflict of Interest}

The authors declare no conflict of interest.

Acknowledgements. We like to thank Gail McMullen for assistance with the animal study, the NIH AIDs reagent repository and Pfizer Inc. for the gift of HIV PIs, and the NIH Fellows Editorial Board for editorial assistance. This research was supported by the Intramural Research Program of the NIH, Center for Cancer Research, National Cancer Institute. The content of this publication does not necessarily reflect the views or policies of the Department of Health and Human Services, nor does mention of trade names, commercial products, or organization imply endorsement by the United States Government.

1. Hightower LE. Heat shock, stress proteins, chaperones, and proteotoxicity. Cell 1991; 66 191-197.

2. Powers ET, Morimoto RI, Dillin A, Kelly JW, Balch WE. Biological and chemical approaches to diseases of proteostasis deficiency. Annu Rev Biochem 2009; 78: 959-991.

3. Ron D. Translational control in the endoplasmic reticulum stress response. J Clin Invest 2002; 110: 1383-1388.

4. Tabas I, Ron D. Integrating the mechanisms of apoptosis induced by endoplasmic reticulum stress. Nat Cell Biol 2011; 13: 184-190.

5. Ma Y, Hendershot LM. ER chaperone functions during normal and stress conditions. J Chem Neuroanat 2004; 28: 51-65.
6. Grant S. Enhancing proteotoxic stress as an anticancer strategy. Oncotarget 2011; 2: 284-286

7. Crawford LJ, Walker B, Irvine AE. Proteasome inhibitors in cancer therapy. J Cell Commun Signal 2011; 5: 101-110.

8. Nawrocki ST, Carew JS, Dunner K Jr, Boise LH, Chiao PJ, Huang P et al. Bortezomib inhibits PKR-like endoplasmic reticulum (ER) kinase and induces apoptosis via ER stress in human pancreatic cancer cells. Cancer Res 2005; 65: 11510-11519.

9. Mimnaugh EG, Xu W, Vos M, Yuan X, Neckers L. Endoplasmic reticulum vacuolization and valosin-containing protein relocalization result from simultaneous hsp90 inhibition by geldanamycin and proteasome inhibition by velcade. Mol Cancer Res 2006; 4: 667-681.

10. Hideshima T, Bradner JE, Wong J, Chauhan D, Richardson P, Schreiber SL et al. Smallmolecule inhibition of proteasome and aggresome function induces synergistic antitumor activity in multiple myeloma. Proc Natl Acad Sci USA 2005; 102: 8567-8572.

11. Nawrocki ST, Carew JS, Pino MS, Highshaw RA, Andtbacka RH, Dunner K Jr et al. Aggresome disruption: a novel strategy to enhance bortezomib-induced apoptosis in pancreatic cancer cells. Cancer Res 2006; 66: 3773-3781.

12. Wang Q, Mora-Jensen $\mathrm{H}$, Weniger MA, Perez-Galan P, Wolford C, Hai T et al. ERAD inhibitors integrate ER stress with an epigenetic mechanism to activate BH3-only protein NOXA in cancer cells. Proc Natl Acad Sci USA 2009; 106: 2200-2205.

13. Schewe DM, Aguirre-Ghiso JA. Inhibition of elF2alpha dephosphorylation maximizes bortezomib efficiency and eliminates quiescent multiple myeloma cells surviving proteasome inhibitor therapy. Cancer Res 2009; 69: 1545-1552.

14. Chow WA, Jiang C, Guan M. Anti-HIV drugs for cancer therapeutics: back to the future? Lancet Oncol 2009; 10: 61-71

15. Gills JJ, Lopiccolo J, Tsurutani J, Shoemaker RH, Best CJ, Abu-Asab MS et al. Nelfinavir, A lead HIV protease inhibitor, is a broad-spectrum, anticancer agent that induces endoplasmic reticulum stress, autophagy, and apoptosis in vitro and in vivo. Clin Cancer Res 2007; 13: 5183-5194.

16. Oyadomari S, Mori M. Roles of CHOP/GADD153 in endoplasmic reticulum stress. Cell Death Differ 2004: 11: 381-389.

17. McCullough KD, Martindale JL, Klotz LO, Aw TY, Holbrook NJ. Gadd153 sensitizes cells to endoplasmic reticulum stress by down-regulating Bcl2 and perturbing the cellular redox state. Mol Cell Biol 2001; 21: 1249-1259.

18. Lin YD, Chen S, Yue P, Zou W, Benbrook DM, Liu S et al. CAAT/enhancer binding protein homologous protein-dependent death receptor 5 induction is a major component of SHetA2-induced apoptosis in lung cancer cells. Cancer Res 2008; 68: 5335-5344.

19. Rodriguez-Gonzalez A, Lin T, Ikeda AK, Simms-Waldrip T, Fu C, Sakamoto KM. Role of the aggresome pathway in cancer: targeting histone deacetylase 6-dependent protein degradation. Cancer Res 2008; 68: 2557-2560.

20. Orlowski RZ, Kuhn DJ. Proteasome inhibitors in cancer therapy: lessons from the first decade. Clin Cancer Res 2008; 14: 1649-1657.

21. Shringarpure R, Catley L, Bhole D, Burger R, Podar K, Tai YT et al. Gene expression analysis of B-lymphoma cells resistant and sensitive to bortezomib. Br J Haematol 2006; 134: $145-156$

22. Oerlemans R, Franke NE, Assaraf YG, Cloos J, van Zantwijk I, Berkers CR et al. Molecular basis of bortezomib resistance: proteasome subunit beta5 (PSMB5) gene mutation and overexpression of PSMB5 protein. Blood 2008; 112: 2489-2499.

23. Smith AJ, Dai H, Correia C, Takahashi R, Lee SH, Schmitz I et al. Noxa/Bcl-2 protein interactions contribute to bortezomib resistance in human lymphoid cells. J Biol Chem 2011; 286: 17682-17692.

24. Bruning A, Vogel M, Mylonas I, Friese K, Burges A. Bortezomib targets the caspase-like proteasome activity in cervical cancer cells, triggering apoptosis that can be enhanced by nelfinavir. Curr Cancer Drug Targets 2011; 11: 799-809.

25. Davies AM, Chansky K, Lara PN Jr, Gumerlock PH, Crowley J, Albain KS et al. Bortezomib plus gemcitabine/carboplatin as first-line treatment of advanced non-small cell lung cancer: a phase II Southwest Oncology Group Study (S0339). J Thorac Oncol 2009; 4: 87-92.

26. Morgillo F, D'Aiuto E, Troiani T, Martinelli E, Cascone T, De Palma R et al. Antitumor activity of bortezomib in human cancer cells with acquired resistance to anti-epidermal growth factor receptor tyrosine kinase inhibitors. Lung Cancer 2011; 71: 283-290.

27. Ramalingam SS, Davies AM, Longmate J, Edelman MJ, Lara PN Jr, Vokes EE et al. Bortezomib for Patients with Advanced-Stage Bronchioloalveolar Carcinoma: A California Cancer Consortium Phase II Study (NCl 7003). J Thorac Oncol 2011; 6: 1741-1745.

28. Wang YC, Kulp SK, Wang D, Yang CC, Sargeant AM, Hung JH et al. Targeting endoplasmic reticulum stress and Akt with OSU-03012 and gefitinib or erlotinib to overcome resistance to epidermal growth factor receptor inhibitors. Cancer Res 2008; 68: 2820-2830.

29. Kraus M, Malenke E, Gogel J, Muller $\mathrm{H}$, Ruckrich T, Overkleeft $\mathrm{H}$ et al. Ritonavir induces endoplasmic reticulum stress and sensitizes sarcoma cells toward bortezomib-induced apoptosis. Mol Cancer Ther 2008; 7: 1940-1948.

30. Mann MJ, Hendershot LM. UPR activation alters chemosensitivity of tumor cells. Cancer Biol Ther 2006; 5: 736-740.

31. Taketani K, Kawauchi J, Tanaka-Okamoto M, Ishizaki H, Tanaka Y, Sakai T et al. Key role of ATF3 in p53-dependent DR5 induction upon DNA damage of human colon cancer cells. Oncogene 2012; 31: 2210-2221.

32. Tian X, Ye J, Alonso-Basanta M, Hahn SM, Koumenis C, Dorsey JF. Modulation of chopdependent DR5 expression by nelfinavir sensitizes glioblastoma multiforme cells to tumor 
necrosis factor-related apoptosis-inducing ligand (TRAIL). J Biol Chem 2011; 286: 29408-29416.

33. Jiang HY, Wek SA, McGrath BC, Lu D, Hai T, Harding HP et al. Activating transcription factor 3 is integral to the eukaryotic initiation factor 2 kinase stress response. Mol Cell Biol 2004; 24: 1365-1377.

34. Voorhees PM, Chen Q, Small GW, Kuhn DJ, Hunsucker SA, Nemeth JA et al. Targeted inhibition of interleukin- 6 with CNTO 328 sensitizes pre-clinical models of multiple myeloma to dexamethasone-mediated cell death. Br J Haematol 2009; 145: 481-490.

35. Skehan P, Storeng R, Scudiero D, Monks A, McMahon J, Vistica D et al. New colorimetric cytotoxicity assay for anticancer-drug screening. J Natl Cancer Inst 1990; 82: 1107-1112.
36. Chou TC. Theoretical basis, experimental design, and computerized simulation of synergism and antagonism in drug combination studies. Pharmacol Rev 2006; 58 : 621-681.

Cell Death and Disease is an open-access journal published by Nature Publishing Group. This work is licensed under the Creative Commons Attribution-NonCommercial-No Derivative Works 3.0 Unported License. To view a copy of this license, visit http://creativecommons.org/licenses/by-nc-nd/3.0/

Supplementary Information accompanies the paper on Cell Death and Disease website (http://www.nature.com/cddis) 